\title{
CT evaluation of small pulmonary vessels area in patients with COPD with severe pulmonary hypertension
}

\author{
Florence Coste, ${ }^{1,2,3}$ Gaël Dournes, ${ }^{1,2,3}$ Claire Dromer, $^{3}$ Elodie Blanchard, ${ }^{3}$ \\ Véronique Freund-Michel, ${ }^{1,2}$ Pierre-Olivier Girodet, 1,2,3 Michel Montaudon, 1,2,3 \\ Fabien Baldacci, ${ }^{4}$ François Picard, ${ }^{3}$ Roger Marthan, ${ }^{1,2,3}$ Patrick Berger, ${ }^{1,2,3}$ \\ François Laurent ${ }^{1,2,3}$
}

\begin{abstract}
- Additional material is published online only. To view please visit the journal online (http://dx.doi.org/10.1136/ thoraxjn-2015-207696).
\end{abstract}

${ }^{1}$ Univ. Bordeaux, Centre de Recherche Cardio-Thoracique de Bordeaux, U1045, Bordeaux, France

${ }^{2}$ Inserm, Centre de Recherche Cardio-Thoracique de Bordeaux, U1045, CIC1401, Bordeaux, France

${ }^{3} \mathrm{CHU}$ de Bordeaux, Service $\mathrm{d}^{\prime}$ Imagerie Thoracique et Cardiovasculaire, Service des Maladies Respiratoires, Service de Cardiologie, CIC1401,

Service d'Explorations Fonctionnelles Respiratoires, Pessac, France

${ }^{4}$ LaBRI, Univ. Bordeaux

Talence, France

\section{Correspondence to}

Professor François Laurent, Centre de Recherche Cardiothoracique de Bordeaux, INSERM U1045, Université Bordeaux, 146 rue Léo Saignat, Bordeaux, Cedex 33076, France; francois. laurent@chu-bordeaux.fr

$\mathrm{FC}$ and GD equal contribution (co-first author)

$\mathrm{PB}$ and $\mathrm{FL}$ equal contribution (co-last author)

Received 13 August 2015 Revised 26 February 2016 Accepted 15 March 2016 Published Online First

15 April 2016

\section{CrossMark}

To cite: Coste $F$

Dournes G, Dromer $C$, et al.

Thorax 2016;71:830-837.

\section{ABSTRACT}

Rationale Severe pulmonary hypertension $(\mathrm{PH})$ is very uncommon in COPD, and a distinct phenotype has been hypothesised. We aimed to evaluate whether $\mathrm{CT}$ can help to recognise this condition non-invasively by measuring small pulmonary vessels.

Material and methods Patients with COPD who underwent pulmonary function tests, unenhanced $\mathrm{CT}$ of the chest and right heart catheterisation (RHC) during a period of stability were included in the study. From 105 included patients, 20 patients with COPD with severe PH (mean pulmonary arterial pressure, $\mathrm{mPAP}>35 \mathrm{~mm} \mathrm{Hg}$ ) were compared with $20 \mathrm{FEV}_{1}$-matched and age-matched patients with COPD with mild or without $\mathrm{PH}$ (mPAP $<35 \mathrm{~mm} \mathrm{Hg}$ ). The percentage of total crosssectional area of vessels less than $5 \mathrm{~mm}^{2}$ normalised by lung area $\left(\% \mathrm{CSA}_{<5}\right)$ and $5-10 \mathrm{~mm}^{2}\left(\% \mathrm{CSA}_{5-10}\right)$, the mean number of cross-sectioned vessels (CSNs) and bronchial wall thickness (WT) were measured on CT examination and compared between groups. Paw scores combining $\mathrm{PaO}_{2}$ measurement and CT parameters best correlated with mPAP were compared by receiver operating characteristic analysis to predict severe $\mathrm{PH}$ in COPD.

Results Patients with severe PH COPD had higher $\% C S A$ and CSN values than those of patients with COPD without severe PH. Using multiple regression analysis, \%CSA $<5$ and WT were the best predictors of mPAP in patients with and without severe $\mathrm{PH}$, respectively. A score combining $\% \mathrm{CSA}_{<5}, \mathrm{PaO}_{2}$ and WT best predicted severe PH in patients with COPD.

Conclusions CT measurements of small vessels support a distinct vessel-related phenotype in patients with COPD with severe $\mathrm{PH}$, and combined with WT and $\mathrm{PaO}_{2}$ parameters in the paw score, which may offer a non-invasive tool to select patients for RHC.

\section{INTRODUCTION}

The development of pulmonary hypertension (PH) in COPD is associated with poor prognosis on mortality and quality of life. ${ }^{1}$ An increase of $10 \mathrm{~mm} \mathrm{Hg}$ in mean pulmonary arterial pressure (mPAP) increases mortality by more than fourfold. ${ }^{2}$ Most of the time, $\mathrm{PH}$ in COPD remains mild to moderate. However, a small proportion of patients develop severe $\mathrm{PH}$, which has been defined by

\section{Key messages}

What is the key question?

- In a population of patients with COPD, are in vivo morphometric changes of the vascular bed observed by $\mathrm{CT}$ able to predict severe pulmonary hypertension?

\section{What is the bottom line?}

- To date, no study has reported in vivo assessment of pulmonary vessels in a very uncommon COPD phenotype associated with severe pulmonary hypertension, and a non-invasive tool for better characterising this population might be useful.

\section{Why read on?}

- CT measurements of small vessels support a distinct vessel-related phenotype in patients with COPD with severe pulmonary hypertension, and combined with wall thickness and $\mathrm{PaO}_{2}$ parameters in the paw score, which may offer a non-invasive tool to select patients for right heart catheterisation or for non-invasive follow-up in longitudinal study.

mPAP higher than $35 \mathrm{~mm} \mathrm{Hg}^{3}{ }^{3}$ Therefore, severe $\mathrm{PH}$ is very uncommon in patients with COPD, ${ }^{3-6}$ ranging from $5 \%$ to $13 \%,{ }^{47}$ and prone to display severe hypoxaemia, hypocapnia and decrease in carbon oxide diffusing capacity. ${ }^{5}$ Though $\mathrm{PH}$ in COPD is classified by the WHO in group $3^{389}$ (ie, $\mathrm{PH}$ associated with lung disease and/or hypoxia), the development of severe $\mathrm{PH}$ in some patients with COPD has been supposed to involve a distinct phenotype related to vessels rather than airways. ${ }^{10}$ CT of the chest has long been used to study noninvasively chronic obstructive diseases. Quantification of bronchi wall areas (WAs) and voxel attenuation of parenchyma has been demonstrated to correlate with airway remodelling and emphysema, respectively. ${ }^{11} 12$ Very recently, we demonstrated a close relationship between pulmonary arterial pressure and bronchial wall thickening, but the vast majority of patients did not present severe $\mathrm{PH} .{ }^{13}$ Although there is a 
paramount literature around quantitative CT of airways in COPD, few data have been reported to quantitative CT of small pulmonary vessels. ${ }^{14-17}$ A single study aimed at evaluating CT assessment of small vessels in COPD subjects with $\mathrm{PH}$ and severe emphysema. ${ }^{16}$ In that study, the degree of mPAP did not exceed the threshold of $40 \mathrm{~mm} \mathrm{Hg}$, so data from CT examinations that could support a distinct vessel alteration among COPD subjects with severe $\mathrm{PH}$ are still lacking. We aimed at evaluating whether CT can provide in vivo evidence about changes of the vascular bed in a population of patients with COPD with severe $\mathrm{PH}$, in order to select patients for right heart catheterisation. For this purpose, we compared the pulmonary function tests (PFTs), CT parameters and mPAP by right heart catheterisation between COPD populations with and without severe $\mathrm{PH}$. Then, we finally aimed to predict the presence of severe $\mathrm{PH}$ in patients with COPD using combined score. Preliminary results of this study have been presented in the form of abstracts. ${ }^{18-20}$

\section{MATERIAL AND METHODS \\ Study population}

Patients with COPD were referred between January 2008 and December 2014 to our institution, a tertiary medical centre for complete examination of $\mathrm{PH}$, before initiation of any treatment. All patients underwent within 1 week: medical questioning, physical examination, 6-minute walk tests (6-MWTs), arterial blood gases, blood tests (including C-reactive protein (CRP), antinuclear antibodies and HIV serology), PFT, transthoracic echocardiography, ventilation/perfusion scintigraphy (V/Q scan), right heart catheterisation (RHC), and unenhanced CT within a minimal period of 1 month of disease stability.
Body plethysmography (BodyBox, Medisoft, Belgium) was used to perform PFT. We chose reference values from the American Thoracic Society ${ }^{21}$ and the European Respiratory Society guidelines. $^{22}$

CT scans were performed on a Somatom Sensation Definition 64 (Siemens, Erlangen, Germany) at full inspiration. Quantitative analysis was performed by using dedicated and validated softwares. $^{23}{ }^{24}$ Automatic quantification of bronchi WA, lumen area, WA per cent (WA\%) and wall thickness (WT) was obtained on orthogonal bronchial cross sections by using the Laplacianof-Gaussian algorithm and homemade software. ${ }^{24} 25$ Automatic quantification of emphysema was assessed with Myrian software (Intrasense, Montpellier, France) using low attenuation area per cent (LAA\%), as previously described. ${ }^{13}$

Automated measurement of small vessel area from CT images was obtained by using the Image J software V.1.40g (a public domain Java image programme available at http://rsb.info.nih. gov/ij/), method detailed elsewhere. ${ }^{14-16}$ The following measurements were obtained: the cross-sectional area of small pulmonary vessel less than $5 \mathrm{~mm}^{2}\left(\% \mathrm{CSA}_{<5}\right)$, and between 5 and $10 \mathrm{~mm}^{2}\left(\% \mathrm{CSA}_{5-10}\right)$, the mean number of cross-sectioned vessels $\mathrm{CSN}_{<5}$ and $\mathrm{CSN}_{5-10}$ normalised by the corresponding lung section area at each CT slice (figure 1). Manual measurements of large vessels were performed on multiplanar reconstruction strictly orthogonal to the main axis of the pulmonary arterial troncus (AP) and the ascending aorta (AO).

\section{Statistical analysis}

NCSS software (NCSS 2001, Kaysville, Utah, USA) was used to assess statistical analyses. p Values $<0.05$ were considered significant. Results were expressed as mean with SD. Comparisons
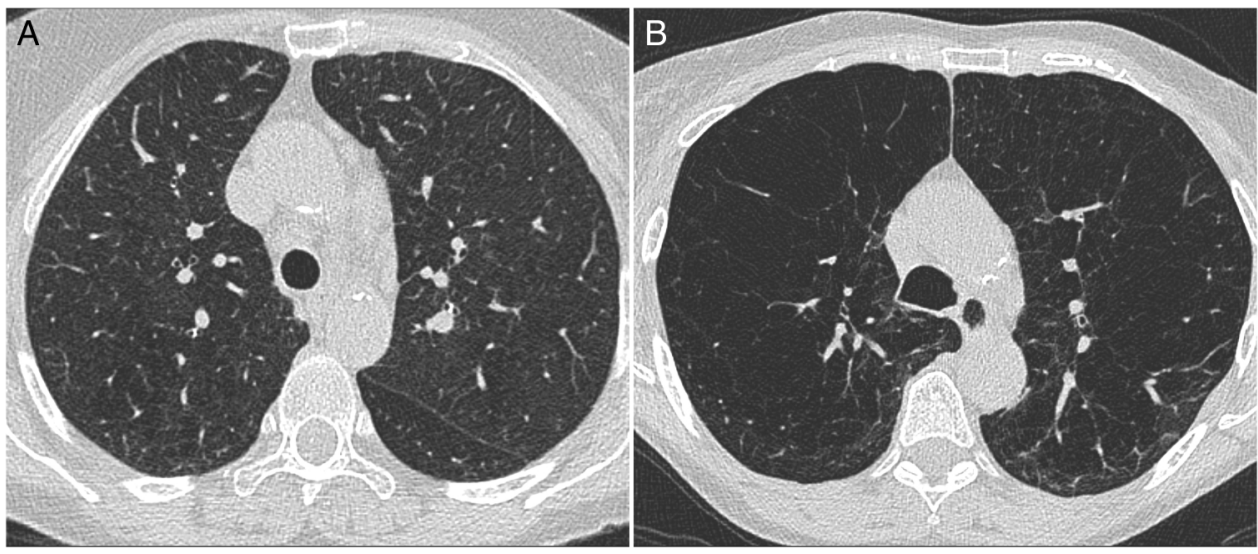

C

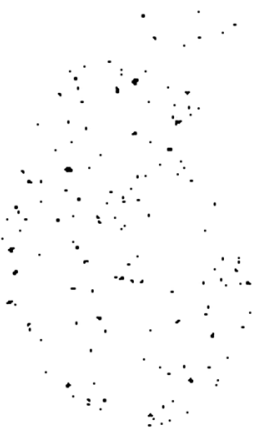

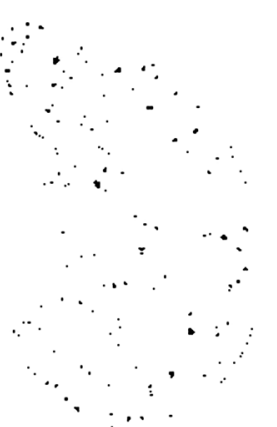

$\mathrm{D}$

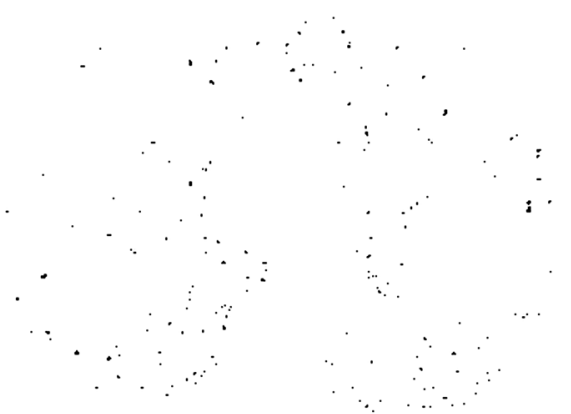

Figure 1 Native isolated CT sections of two representative patients with COPD with (A) and without (B) severe PH. After thresholding and conversion into binary image, a mask was applied to analyse only circular particle ranging from 0 to $5 \mathrm{~mm}^{2}$, (C and $\left.D\right)$ representing the corresponding postprocessing CT sections, respectively. Note that the number of small vessel sections is visually different in both subjects. 
Table 1 Variables and range used for computation of the paw score standardisation using quartile range

\begin{tabular}{lllll}
\hline \multirow{5}{*}{ Variables } & $\mathbf{0}$ & $\mathbf{1}$ & $\mathbf{2}$ & $\mathbf{3}$ \\
\cline { 2 - 5 } $\mathrm{PaO}_{2}(\mathrm{~mm} \mathrm{Hg})$ & $\geq 64.5$ & $(51.5-64.4)$ & $(46.5-51.4)$ & $<46.5$ \\
$\% \mathrm{CSA}_{<5}$ & $<0.313$ & $(0.313-0.432)$ & $(0.433-0.547)$ & $\geq 0.548$ \\
WT & $<1.095$ & $(1.095-1.179)$ & $(1.180-1.324)$ & $\geq 1.325$
\end{tabular}

WT, mean wall thickness; $\% \mathrm{CSA}_{<5}$, percentage of total lung area taken up by the cross-sectional area of pulmonary vessels less than $5 \mathrm{~mm}^{2}$.

were performed by using t tests. Parameters that were not normally distributed were expressed as median with IQRs and analysed by Mann-Whitney tests. Categorical variables were tested with Fisher's exact tests. Univariate correlations were assessed using Pearson product-moment coefficients. Identification of the strength of the association between MPAP and other variables was assessed using forward stepwise multiple regression analyses. To predict severe $\mathrm{PH}$, we built four scores (ie, paw scores), combining two to three variables, best correlated to mPAP, the higher value indicating a higher risk of severe $\mathrm{PH}$ (table 1). Scores were compared by using areas under the curve (AUCs) of receiver operating characteristic (ROC) curves.

For details about PFT, RHC, CT protocols or echocardiography and statistical analysis, see the online supplemental methods section.

\section{RESULTS}

\section{Study populations}

From a total of 198 selected patients, 105 patients with COPD were included in the study, with no other condition susceptible to explain $\mathrm{PH}$ (see figure 2 and table 2). Among the 105 patients with COPD, 20 patients demonstrated severe $\mathrm{PH}$, as defined by mPAP at RHC superior to $35 \mathrm{~mm} \mathrm{Hg}$, as the last world $\mathrm{PH}$ symposium proposed this cut-off. ${ }^{3}$ These severe patients with $\mathrm{PH}$ were $\mathrm{FEV}_{1}$-matched and age-matched to 20 other patients with COPD without severe PH (mPAP $<35 \mathrm{~mm} \mathrm{Hg}$ ) (table 2). The 65 remaining patients unable to be matched were presented separately (see online supplementary table S1).

Demographic characteristics, pulmonary functions and clinical, hemodynamic and biological data of both study populations are shown in table 2. There was no difference in demographic characteristics, CRP levels and lung function parameters between patients with COPD with and without severe $\mathrm{PH}$, except for transfert lung capacity of carbon monoxide (TLCO). The patients with COPD with severe $\mathrm{PH}$ had significantly lower values of both TLCO and 6-MWT, deeper hypoxia and higher brain natriuretic peptide (BNP) levels. There was no left ventricular dysfunction in both groups (data not shown). All patients with COPD carried out RHC. The mPAP ranged from 35 to $58 \mathrm{~mm} \mathrm{Hg}$ and from 13 to $34 \mathrm{~mm} \mathrm{Hg}$ in patients with severe $\mathrm{PH}$ and without severe $\mathrm{PH}$, respectively. Moreover, a precapillary $\mathrm{PH}$ was demonstrated in all patients with COPD with $\mathrm{PH}$, as assessed by pulmonary capillary wedge pressure (PCWP) values less than $15 \mathrm{~mm} \mathrm{Hg}$ and gradient values superior to $10 \mathrm{~mm} \mathrm{Hg}$.

\section{Relationship between mPAP and quantitative CT parameters} Morphological CT parameters were assessed in both groups of patients with COPD (table 3). At alveolar level, emphysema (LAA\%) was not significantly different between the two groups, and there was no significant correlation between emphysema and mPAP (see online supplementary table S2).

At the bronchial level, no significant difference was observed between patients with COPD with and without severe $\mathrm{PH}$ (table 3).

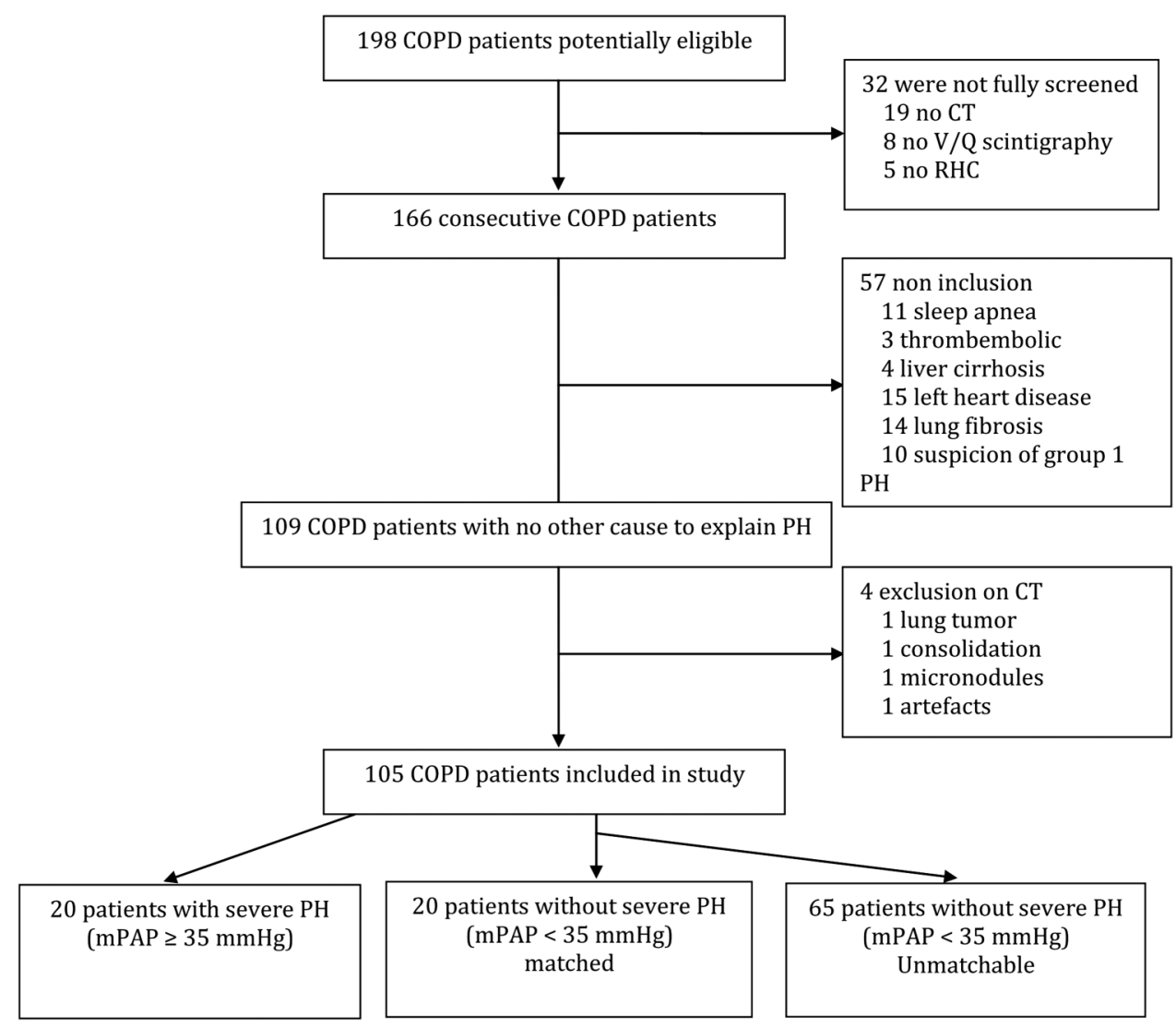

Figure 2 Study design. mPAP, mean pulmonary arterial pressure; PH, pulmonary hypertension; RHC, right heart catheterisation. 
However, for both groups, bronchial WT was positively correlated with mPAP (see online supplementary table S2).

At the vascular level, the ratio of the main pulmonary artery to the ascending aorta diameter $(\mathrm{AP} / \mathrm{AO})$ was greater in patients with COPD with severe $\mathrm{PH}$ than in patients without severe $\mathrm{PH}$ (table 3). AP/AO was not correlated to mPAP in patients with COPD with severe PH (see online supplementary table S2). However, a positive correlation was found between mPAP and $\mathrm{AP} / \mathrm{AO}$ in the group of patients with $\mathrm{COPD}$ without severe $\mathrm{PH}$ (see online supplementary table S2, figure 3A, C). All parameters related to small vessels (ie, $\% \mathrm{CSA}_{<5}, \% \mathrm{CSA}_{5-10}, \mathrm{CSN}_{<5}$ and $\mathrm{CSN}_{5-10}$ ) were greater in patients with COPD with severe $\mathrm{PH}$ than in patients without severe $\mathrm{PH}$ (table 3). In patients with severe $\mathrm{PH}$, a positive correlation was found between mPAP

Table 2 Characteristics of COPD subjects

\begin{tabular}{|c|c|c|c|}
\hline & $\begin{array}{l}\text { COPD subjects } \\
\text { with severe PH }\end{array}$ & $\begin{array}{l}\text { COPD subjects } \\
\text { without severe PH }\end{array}$ & $\mathrm{p}$ Value \\
\hline $\mathrm{N}$ & 20 & 20 & \\
\hline \multicolumn{4}{|l|}{ Age } \\
\hline Years & $67 \pm 9$ & $66 \pm 8$ & 0.766 \\
\hline \multicolumn{4}{|l|}{ Sex ratio } \\
\hline Men/women & $17 / 3$ & $15 / 5$ & 0.693 \\
\hline \multicolumn{4}{|l|}{ BMI } \\
\hline $\mathrm{kg} / \mathrm{m}^{2}$ & $26 \pm 5$ & $24 \pm 4$ & 0.123 \\
\hline \multicolumn{4}{|l|}{ Tobacco } \\
\hline Smoking status (Y/N) & $20 / 0$ & $20 / 0$ & \\
\hline Current smoker (Y/N) & $5 / 15$ & $7 / 13$ & 0.731 \\
\hline Pack year (no) & $31(11-47)$ & $31(25-40)$ & 0.978 \\
\hline \multicolumn{4}{|l|}{ PFT } \\
\hline $\mathrm{FEV}_{1}(\%$ pred $)$ & $52 \pm 21$ & $52 \pm 21$ & 0.983 \\
\hline $\mathrm{FEV}_{1} / \mathrm{FVC}(\%)$ & $54 \pm 15$ & $50 \pm 15$ & 0.380 \\
\hline TLC (\%) & $99(92-105)$ & $107(94-130)$ & 0.182 \\
\hline RV (\%) & $124(98-148)$ & $134(102-225)$ & 0.579 \\
\hline TLCO (\%) & $24 \pm 10$ & $40 \pm 22$ & 0.008 \\
\hline \multicolumn{4}{|l|}{ Six-minute walk test } \\
\hline Distance $(\mathrm{m})$ & $271 \pm 100$ & $370 \pm 68$ & 0.003 \\
\hline \multicolumn{4}{|c|}{ Arterial blood gases (ambient air) } \\
\hline $\mathrm{PaO}_{2}(\mathrm{~mm} \mathrm{Hg})$ & $51 \pm 6$ & $59 \pm 13$ & 0.014 \\
\hline $\mathrm{PaCO}_{2}(\mathrm{~mm} \mathrm{Hg})$ & $36(29-41)$ & $37(34-43)$ & 0.228 \\
\hline \multicolumn{4}{|l|}{ Right heart catheterisation } \\
\hline mPAP (mm Hg) & $45 \pm 6$ & $25 \pm 5$ & $<0.001$ \\
\hline sPAP (mm Hg) & $70 \pm 14$ & $39 \pm 8$ & $<0.001$ \\
\hline $\mathrm{dPAP}(\mathrm{mm} \mathrm{Hg})$ & $28 \pm 4$ & $15 \pm 4$ & $<0.001$ \\
\hline PCWP (mmHg) & $9 \pm 2$ & $7 \pm 3$ & 0.012 \\
\hline Gradient $(\mathrm{mm} \mathrm{Hg})$ & $20 \pm 4$ & $9 \pm 3$ & $<0.001$ \\
\hline PVR (Wood unit) & $8 \pm 2$ & $4 \pm 1$ & $<0.001$ \\
\hline $\mathrm{PVR}_{\mathrm{i}}\left(\right.$ Wood unit $\left./ \mathrm{m}^{2}\right)$ & $14 \pm 5$ & $7 \pm 1$ & $<0.001$ \\
\hline Cardiac output (L/min) & $5 \pm 1.2$ & $5 \pm 1.2$ & 0.557 \\
\hline Cardiac index $\left(\mathrm{L} / \mathrm{min} / \mathrm{m}^{2}\right)$ & $3 \pm 0.7$ & $3 \pm 0.5$ & 0.556 \\
\hline \multicolumn{4}{|l|}{ Biology } \\
\hline $\mathrm{CRP}(\mathrm{pg} / \mathrm{mL})$ & $5 \pm 3$ & $6 \pm 2$ & 0.377 \\
\hline BNP $(\mathrm{mg} / \mathrm{mL})$ & $481 \pm 114$ & $177 \pm 215$ & 0.019 \\
\hline
\end{tabular}

Severe PH in COPD is defined $\mathrm{mPAP} \geq 35 \mathrm{~mm} \mathrm{Hg}$, without $<35 \mathrm{~mm} \mathrm{Hg}$. Data are means \pm SD for continuous normal variables, or median with IQR if their distribution is not normal. Comparisons of continuous variables were made with the $t$ tests or with Mann-Whitney tests for non-parametric variables. Categorical variables were analysed with Fisher's exact tests.

$\mathrm{BMI}$, body mass index; BNP, brain natriuretic peptide; CRP, C reactive protein Gradient, dPAP-PCWP; $m$, s, dPAP, mean, systolic, diastolic pulmonary arterial pressure; PCWP, pulmonary capillary wedge pressure; PFT, pulmonary function test; $\mathrm{PH}$, pulmonary hypertension; pred, predicted; PVR, pulmonary vascular resistance; $\mathrm{PVR}_{\mathrm{i}}$, indexed PVR; RV= residual volume; TLC= total lung capacity; $T L C O=$ transfert lung capacity of carbon monoxide. and $\% \mathrm{CSA}_{<5}$. Conversely, in patients without severe $\mathrm{PH}, \mathrm{mPAP}$ was negatively correlated to $\% \mathrm{CSA}_{<5}$ (figure $2 \mathrm{~B}, \mathrm{D}$ ).

\section{Factors influencing mPAP}

Regarding variables from PFT, arterial blood gases, biology, CT and 6-MWT, in COPD without severe $\mathrm{PH}$, significant univariate correlations were found between $\mathrm{mPAP}$ and various variables including $\mathrm{PaO}_{2}$, TLCO\%, BNP, AP/AO ratio, bronchial WT, CSAs and 6-MWT (see online supplementary table S2). Conversely, in patients with COPD with severe $\mathrm{PH}$, significant correlations were found only between mPAP and both WT and CSAs (see online supplementary table S2).

Significant variables that were correlated with mPAP and not cross-correlated (see online supplementary tables S3 and S4) were entered in stepwise multiple regression analyses in order to find the best model fitting mPAP within the two groups of patients with COPD (table 4). In patients with severe $\mathrm{PH}$, the best model associated WT, $\% \mathrm{CSA}_{<5}$ and $\mathrm{PaO}_{2}$ and explained $65 \%$ of the mPAP variations. Among these variables, mean $\% \mathrm{CSA}_{<5}$ explained $36 \%$ of the mPAP variations alone, whereas WT and $\mathrm{PaO}_{2}$ explained only $29 \%$ and $3 \%$, respectively. In patients with COPD without severe $\mathrm{PH}$, the best model explained 69\% of mPAP variations, WT was the main factor explaining mPAP (26\%), whereas $\mathrm{PaO}_{2}$ and $\% \mathrm{CSA}_{<5}$ explaining $13 \%$ and 9\% of mPAP variations, respectively.

\section{Factors predicting severe $\mathrm{PH}$}

Since $\% \mathrm{CSA}_{<5}$ was correlated to mPAP in opposite ways in patients with and without severe $\mathrm{PH}$, it seems hard to predict the presence of severe $\mathrm{PH}$ in patients with COPD using \% $\mathrm{CSA}_{<5}$ only. We thus built four combined paw scores using two

Table 3 Comparison of CT parameters between groups

\begin{tabular}{|c|c|c|c|}
\hline & $\begin{array}{l}\text { COPD subjects } \\
\text { with severe PH }\end{array}$ & $\begin{array}{l}\text { COPD subjects } \\
\text { without severe } \\
\text { PH }\end{array}$ & $p$ Value \\
\hline $\mathrm{N}$ & 20 & 20 & \\
\hline \multicolumn{4}{|l|}{ Bronchi } \\
\hline WA & $19.06 \pm 5.17$ & $20.16 \pm 4.76$ & 0.490 \\
\hline Mean lumen area $\left(\mathrm{mm}^{2}\right)$ & $11.14 \pm 4.67$ & $14.30 \pm 5.60$ & 0.060 \\
\hline WA\% & $1.91 \pm 0.62$ & $1.62 \pm 0.40$ & 0.079 \\
\hline Mean wall thickness (mm) & $1.22 \pm 0.14$ & $1.18 \pm 0.14$ & 0.401 \\
\hline \multicolumn{4}{|l|}{ Parenchyma } \\
\hline \multicolumn{4}{|l|}{ Emphysema } \\
\hline $\begin{array}{l}\text { Low lung attenuation area } \\
\text { per cent }\end{array}$ & $11.85 \pm 14.59$ & $16.97 \pm 13.54$ & 0.257 \\
\hline \multicolumn{4}{|l|}{ Vessels } \\
\hline \multicolumn{4}{|l|}{ Large vessels } \\
\hline APIAO & $1.04 \pm 0.13$ & $0.91 \pm 0.21$ & 0.022 \\
\hline \multicolumn{4}{|l|}{ Small vessels } \\
\hline$\% \mathrm{CSA}_{<5}$ & $0.52 \pm 0.19$ & $0.39 \pm 0.14$ & 0.019 \\
\hline$\% \mathrm{CSA}_{5-10}$ & $0.16 \pm 0.03$ & $0.12 \pm 0.03$ & $<0.001$ \\
\hline $\mathrm{CSN}_{<5}$ & $0.32(0.25-0.49)$ & $0.22(0.19-0.36)$ & 0.034 \\
\hline $\mathrm{CSN}_{5-10}$ & $0.02(0.02-0.02)$ & $0.01(0.01-0.02)$ & $<0.001$ \\
\hline
\end{tabular}

Data are means with SD for continuous normal variables, or median with IQR if their distribution is not normal. Comparisons of continuous variables were made with the $\mathrm{t}$ tests, or with Mann-Whitney tests for non-parametric variables.

$\% \mathrm{CSA}_{<5}$, percentage of total lung area taken up by the cross-sectional area of pulmonary vessels less than $5 \mathrm{~mm}^{2} ; \% \mathrm{CSA}_{5-10}$, percentage of total lung area taken up by the cross-sectional area of pulmonary vessels between 5 and $10 \mathrm{~mm}^{2} ; \mathrm{AO}$ aorta; $\mathrm{AP}$, pulmonary artery troncus; $\mathrm{CSN}_{<5}$, number of vessels less than $5 \mathrm{~mm}^{2}$ normalised by total lung area; $\mathrm{CSN}_{5-10}$, number of vessels between 5 and $10 \mathrm{~mm}^{2}$ normalised by total lung area; $\mathrm{PH}$, pulmonary hypertension; WA, mean wall area $\left(\mathrm{mm}^{2}\right)$; WA\%, mean wall area percentage. 

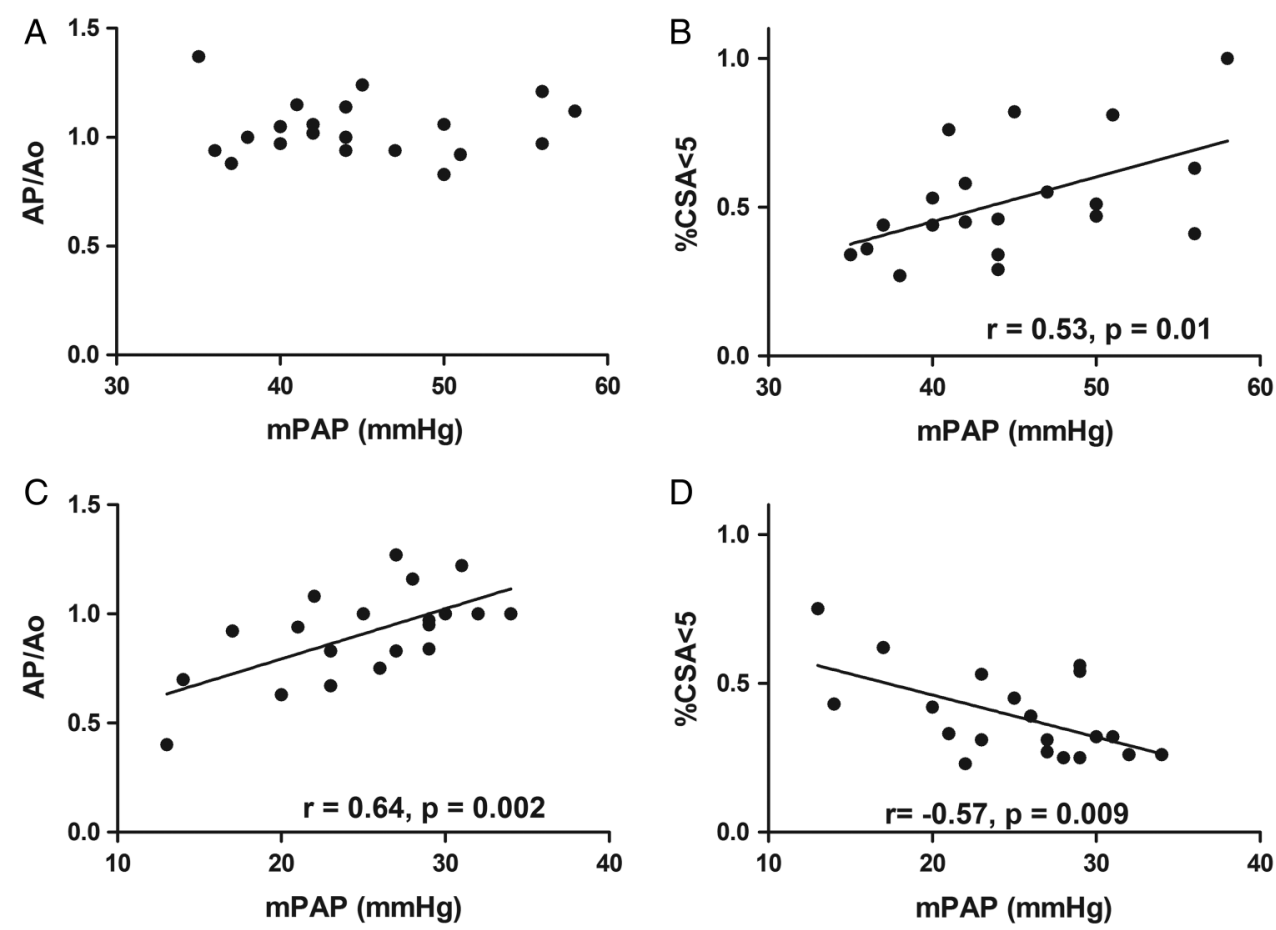

Figure 3 Correlation between mean pulmonary arterial pressure (mPAP) and CT parameters such as ratio of pulmonary artery troncus to aorta diameter (AP/Ao), \% cross-sectional area (\%CSA). (A and B) represent patients with COPD with severe pulmonary hypertension (PH). (C and D) represent patients with COPD without severe $\mathrm{PH}$.

to three variables best correlated to $\operatorname{mPAP}$ (ie, \%CSA $<5$, WT, $\left.\mathrm{PaO}_{2}\right)$ and assessed their corresponding ROC curves for the 40 matched patients and for all the 105 included patients (see online supplementary figures S1 and S2). Characteristics of these ROC curves for each combination are reported in table 5. For the 40 matched patients, AUCs from each combination including $\% \mathrm{CSA}_{<5}$ were significant and greater than 0.5 . The best paw score associated the three variables $\% \mathrm{CSA}_{<5}, \mathrm{PaO}_{2}$ and WT and allowed a high negative predictive value (NPV) of $95 \%$ with a sensitivity and specificity of $75 \%$ and $70 \%$, respectively. These results were confirmed with all the 105 patients initially included in the study: AUCs from each combination were also significant and greater than 0.5 , and the paw score that associates the three variables allowed even greater NPV and specificity, and the sensitivity is unchanged.

\section{DISCUSSION}

Taken together, this study demonstrated that mPAP can be predicted differently in patients with COPD with and without severe $\mathrm{PH}$ by using CT. In patients with severe $\mathrm{PH}$, increased small pulmonary vessels area $\left(\% \mathrm{CSA}_{<5}\right)$ is the factor mostly associated with mPAP elevation, whereas it is increased WT in patients without severe $\mathrm{PH}$. The $\% \mathrm{CSA}_{<5}$, WT and $\mathrm{PaO}_{2}$ were the three best correlated parameters with mPAP. These three variables could be combined to build a paw score helpful for predicting the absence of severe $\mathrm{PH}$ in patients with COPD.

Identifying clinically meaningful COPD phenotypes is of critical importance for patient care, ${ }^{26} 27$ since COPD is a complex and heterogeneous disease that the sole $\mathrm{FEV}_{1} / \mathrm{FVC}$ cut-off of $70 \%$ cannot describe adequately. ${ }^{28}$ To better characterise patients with COPD on the basis of attributes that differ between individuals and relate with clinically relevant outcomes, CT has long been shown to provide invaluable clues by allowing non-invasive and quantitative assessment of structural alterations from bronchi and lung parenchyma. ${ }^{29-31}$ However, few studies have focused on vessel modifications in COPD subjects, ${ }^{14-17} 32$ though there are compelling evidence that COPD is also mediated by a pulmonary vascular disease. ${ }^{33-35}$ It has been shown that the toxicity of tobacco smoke affects bronchi and parenchyma, but can also directly alter vessels in both animals

Table 4 Multivariate analysis of MPAP in patients with COPD with and without severe PH

\begin{tabular}{|c|c|c|c|c|c|}
\hline Population studied & Model & Independent variables & Partial $\mathbf{R}^{2}$ & $\begin{array}{l}\text { Increase in mPAP per unit increase } \\
\text { in independent variable }(\mathrm{mm} \mathrm{Hg})\end{array}$ & p Value \\
\hline COPD subjects with severe $\mathrm{PH}$ & $\begin{array}{l}R^{2}=0.65 ; p<0.007 \\
F=9.6\end{array}$ & $\begin{array}{l}\mathrm{PaO}_{2} \\
\text { WT }\end{array}$ & $\begin{array}{l}0.03 \\
0.29\end{array}$ & $\begin{array}{l}-0.18 \\
26.3\end{array}$ & $\begin{array}{l}0.250 \\
0.002\end{array}$ \\
\hline$(n=20)$ & Mean square error $=19.6$ & $\% \mathrm{CSA}_{<5}$ & 0.36 & 21.1 & 0.001 \\
\hline COPD subjects without severe PH & $\begin{array}{l}R^{2}=0.69 ; p<0.0002 \\
F=12.1\end{array}$ & $\begin{array}{l}\mathrm{PaO}_{2} \\
\text { WT }\end{array}$ & $\begin{array}{l}0.13 \\
0.26\end{array}$ & $\begin{array}{l}-0.17 \\
22.0\end{array}$ & $\begin{array}{l}0.020 \\
0.002\end{array}$ \\
\hline$(n=20)$ & Mean square error $=12.34$ & $\% \mathrm{CSA}_{<5}$ & 0.09 & -13.5 & 0.040 \\
\hline
\end{tabular}


Table 5 Receiver operating characteristic curve analyses predicting the presence of mPAP $>35 \mathrm{~mm} \mathrm{Hg}$

\begin{tabular}{|c|c|c|c|c|c|c|c|c|c|}
\hline \multirow[b]{2}{*}{ Paw scores } & \multirow[b]{2}{*}{ AUC } & \multirow[b]{2}{*}{ AUC's SE } & \multirow[b]{2}{*}{$p$ Value } & \multirow[b]{2}{*}{ Sensitivity } & \multirow[b]{2}{*}{ Specificity } & \multicolumn{2}{|c|}{ Positive predictive value } & \multicolumn{2}{|c|}{ Negative predictive value } \\
\hline & & & & & & $5 \%$ prev & $13 \%$ prev & $5 \%$ prev & $13 \%$ prev \\
\hline \multicolumn{10}{|l|}{40 patients } \\
\hline$\% \mathrm{CSA}_{<5}+\mathrm{PaO}_{2}+\mathrm{WT}$ & 0.790 & 0.073 & $<0.001$ & $\begin{array}{l}0.750 \\
(0.615 \text { to } 0.884)\end{array}$ & $\begin{array}{l}0.700 \\
(0.557 \text { to } 0.842)\end{array}$ & $\begin{array}{l}0.116 \\
(0.016 \text { to } 0.215)\end{array}$ & $\begin{array}{l}0.272 \\
(0.134 \text { to } 0.409)\end{array}$ & $\begin{array}{l}0.982 \\
\text { (0.940 to } 1.000)\end{array}$ & $\begin{array}{l}0.949 \\
(0.880 \text { to } 1.000)\end{array}$ \\
\hline$\% \mathrm{CSA}_{<5}+\mathrm{PaO}_{2}$ & 0.796 & 0.069 & 0.004 & $\begin{array}{l}0.700 \\
\text { (0.557 to } 0.842)\end{array}$ & $\begin{array}{l}0.800 \\
(0.676 \text { to } 0.923)\end{array}$ & $\begin{array}{l}0.156 \\
(0.043 \text { to } 0.268)\end{array}$ & $\begin{array}{l}0.343 \\
(0.195 \text { to } 0.490)\end{array}$ & $\begin{array}{l}0.981 \\
\text { (0.938 to } 1.000)\end{array}$ & $\begin{array}{l}0.947 \\
\text { (0.877 to } 1.000)\end{array}$ \\
\hline$\% \mathrm{CSA}_{<5}+\mathrm{WT}$ & 0.741 & 0.079 & 0.002 & $\begin{array}{l}0.650 \\
\text { (0.502 to } 0.797)\end{array}$ & $\begin{array}{l}0.800 \\
(0.676 \text { to } 0.923)\end{array}$ & $\begin{array}{l}0.146 \\
(0.036 \text { to } 0.255)\end{array}$ & $\begin{array}{l}0.327 \\
(0.181 \text { to } 0.472)\end{array}$ & $\begin{array}{l}0.977 \\
\text { (0.930 to } 1.000)\end{array}$ & $\begin{array}{l}0.939 \\
\text { (0.864 to } 1.000)\end{array}$ \\
\hline $\begin{array}{r}\mathrm{PaO}_{2}+\mathrm{WT} \\
105 \text { patients }\end{array}$ & \multicolumn{8}{|c|}{105 patients } & ND \\
\hline$\% \mathrm{CSA}_{<5}+\mathrm{PaO}_{2}+\mathrm{WT}$ & 0.828 & 0.050 & $<0.001$ & $\begin{array}{l}0.750 \\
(0.667 \text { to } 0.832)\end{array}$ & $\begin{array}{l}0.800 \\
(0.723 \text { to } 0.876)\end{array}$ & $\begin{array}{l}0.165 \\
(0.094 \text { to } 0.235)\end{array}$ & $\begin{array}{l}0.359 \\
(0.267 \text { to } 0.450)\end{array}$ & $\begin{array}{l}0.984 \\
\text { (0.959 to } 1.000)\end{array}$ & $\begin{array}{l}0.955 \\
(0.915 \text { to } 0.994)\end{array}$ \\
\hline$\% \mathrm{CSA}_{<5}+\mathrm{PaO}_{2}$ & 0.839 & 0.043 & $<0.001$ & $\begin{array}{l}0.950 \\
\text { (0.908 to } 0.991)\end{array}$ & $\begin{array}{l}0.538 \\
(0.442 \text { to } 0.663)\end{array}$ & $\begin{array}{l}0.038 \\
(0.001 \text { to } 0.074)\end{array}$ & $\begin{array}{l}0.235 \\
(0.153 \text { to } 0.316)\end{array}$ & $\begin{array}{l}0.995 \\
\text { (0.981 to } 1.000)\end{array}$ & $\begin{array}{l}0.986 \\
\text { (0.963 to } 1.000)\end{array}$ \\
\hline$\% \mathrm{CSA}_{<5}+\mathrm{WT}$ & 0.765 & 0.060 & $<0.001$ & $\begin{array}{l}0.650 \\
(0.558 \text { to } 0.741)\end{array}$ & $\begin{array}{l}0.825 \\
(0.752 \text { to } 0.897)\end{array}$ & $\begin{array}{l}0.164 \\
(0.093 \text { to } 0.234)\end{array}$ & $\begin{array}{l}0.357 \\
(0.265 \text { to } 0.448)\end{array}$ & $\begin{array}{l}0.978 \\
(0.949 \text { to } 1.000)\end{array}$ & $\begin{array}{l}0.940 \\
(0.894 \text { to } 0.985)\end{array}$ \\
\hline $\mathrm{PaO}_{2}+\mathrm{WT}$ & 0.738 & 0.056 & $<0.001$ & $\begin{array}{l}0.750 \\
(0.667 \text { to } 0.832)\end{array}$ & $\begin{array}{l}0.613 \\
(0.519 \text { to } 0.706)\end{array}$ & $\begin{array}{l}0.092 \\
(0.036 \text { to } 0.147)\end{array}$ & $\begin{array}{l}0.224 \\
(0.144 \text { to } 0.303)\end{array}$ & $\begin{array}{l}0.979 \\
\text { (0.951 to } 1.000)\end{array}$ & $\begin{array}{l}0.943 \\
(0.898 \text { to } 0.987)\end{array}$ \\
\hline
\end{tabular}

Data are absolute number with $95 \% \mathrm{Cl}$.

AUC, area under curve; $\% \mathrm{CSA}_{<5}$, percentage of total lung area taken up by the cross-sectional area of pulmonary vessels less than 5 mm ${ }^{2}$; mPAP, mean pulmonary arterial pressure; $\mathrm{ND}$, not determined; $\mathrm{PaO}_{2}$, oxygen arterial partial pressure $(\mathrm{mm} \mathrm{Hg})$; prev, prevalence of severe PH in the COPD population; WT, mean wall thickness (mm).

and humans. ${ }^{36}$ We hypothesised that CT measurement of intrapulmonary vessels, especially the more distal ones, could be a tool to characterise COPD subjects in addition to standard measurements of emphysema and bronchial thickness. ${ }^{13}$

In the present study, we focused our attention towards a population of patients with COPD suffering from severe $\mathrm{PH}$. We paid a special attention to select patients without severe $\mathrm{PH}$ as close as possible to those with severe $\mathrm{PH}$ in terms of age and $\mathrm{FEV}_{1}$ to limit potential bias on demographic and functional differences. Thus, the clinical features of patients with severe $\mathrm{PH}$ shared close similarities to those without severe PH. For instance, the tobacco smoke consumption was not different between groups, which suggest a different susceptibility against tobacco toxicity. However, severe PH in COPD is occasional, as observed previously, ${ }^{4} 5$ and there is, up to now, no clear evidence to explain its aetiology. ${ }^{10}$ In the study of Chaouat et al, ${ }^{5}$ none of the PFT parameters, emphysema or hypoxaemia were found to be predictors of $\mathrm{PH}$ in an univariate analysis of mPAP in a population of 11 patients with COPD with severe $\mathrm{PH}$ and no other condition susceptible to explain $\mathrm{PH}$. Thus, it was supposed that severe $\mathrm{PH}$ in COPD was more likely explained by a vascular alteration rather than an airway disease. In patients with severe $\mathrm{PH}$ from the present study, \%CSAs and WT were found to be predictors of mPAP, while $\mathrm{PaO}_{2}, \mathrm{FEV}_{1} \%$, TLCO $\%$ and LAA $\%$ were not. The main morphological parameter able to explain mPAP variation in this population was $\% \mathrm{CSA}_{<5}$, suggesting a striking difference in the pathophysiology of increased mPAP between the two populations of COPD. By applying a previously reported method for quantifying small vessels on CT examinations, ${ }^{16}$ we have found that both $\% \mathrm{CSA}_{<5}$ and $\% \mathrm{CSA}_{5-10}$ were higher in patients with COPD with severe $\mathrm{PH}$ compared with those without severe $\mathrm{PH}$. In this latter population, at univariate analysis, both $\mathrm{PaO}_{2}$ and TLCO\% were found to be correlated with mPAP, a finding consistent with the central role played by hypoxaemia in the development of PH. ${ }^{5} 37$ There was a lack of correlation between emphysema and $\mathrm{PH}$, which is in line with previous studies. ${ }^{13} 16^{37}$ In addition, we recently reported that the main parameter able to explain mPAP in patients with COPD without severe $\mathrm{PH}$ was $\mathrm{WT},{ }^{13}$ which was confirmed in this study.

Correlations between \%CSAs and mPAP found herein deserve further comments. In the literature evaluation of \%CSAs values in COPD subjects with $\mathrm{PH}$ was significantly negatively correlated, as in our population of COPD without severe PH. This result was ascribed to reduced distensibility of small vessels, hypoxic vasoconstriction and vessel destruction secondary to emphysema. ${ }^{1638}$ However, this study was performed based on a population of COPD subjects with severe emphysema, as assessed by a visual of percentage of emphysema on CT scans superior to $75 \%,{ }^{7} 16$ and corresponding to total automatic quantification (LAA\%) of $25 \%$, and in which the degree of mPAP elevation did not exceed the threshold of severe PH. This difference between subjective visual grading and objective automatic quantification with LAA\% of emphysema is already described in the literature. ${ }^{11}$ In our population with severe $\mathrm{PH}$ by contrast, the correlation between \%CSAs and mPAP was positive. Thus, our results are complementary from the previous report of Matsuoka et al, ${ }^{16}$ and bring additional insight into the ability of CT to discriminate COPD phenotypes on a small vessel-based analysis. Moreover, a marker for PH in COPD (ie, $\mathrm{AP} / \mathrm{AO})^{39}$ was not correlated to mPAP in our COPD population with severe $\mathrm{PH}$.

In this COPD population, the absence of severe $\mathrm{PH}$ could be well predicted by the paw score (ie, combination of $\mathrm{PaO}_{2}$, WT and $\left.\% \mathrm{CSA}_{<5}\right)$, as demonstrated by the ROC curve analysis. The distal vascular parameter $\% \mathrm{CSA}_{<5}$ was needed, whatever the combination of parameters tested to significantly distinguish between severe $\mathrm{PH}$ and others, emphasising the role of distal vessels changes in severe $\mathrm{PH}$ of COPD. Interestingly, the best paw score allowed us to discriminate, non-invasively, matched patients with COPD with severe $\mathrm{PH}$ from patients with COPD without severe $\mathrm{PH}$. From the perspective of clinical conditions, patients with paw score higher than 5 should be selected to perform RHC. Indeed, whereas the NPV was very high (95\%- 
$98 \%)$, the positive predictive value was low (12\%-27\%). We confirmed the clinical interest of this paw score in a larger group of patients with COPD $(n=105)$. However, these results could be interestingly confirmed in a new prospective cohort. Since the prevalence of severe PH in COPD is low, ${ }^{3-5} 7$ it is thus necessary to better characterise these patients whom reports are still limited in number of subjects. ${ }^{4}{ }^{40}$

Several limitations can be discussed in this study. The study was observational and retrospective. It was not possible to draw causal relationship between increased size and number of small vessels and severe degree of $\mathrm{PH}$ in COPD. However, mild-to-moderate $\mathrm{PH}$ in COPD is commonly thought to be caused by the destruction of small pulmonary vessels as a consequence of emphysema, or secondary to vasoconstriction in response to hypoxia. To support these hypotheses, mild-to-moderate PH in COPD has been consistently reported to be related with a reduction of small vessel areas ${ }^{16}$ or volume $^{38}$ at CT examination. Our study is the first to report in vivo data on the distal vascular bed in patients with COPD with severe $\mathrm{PH}$. Moreover, this study indicates that, in this subpopulation of COPD, development of $\mathrm{PH}$ is not related to a decrease but to an increase in pulmonary vasculature area. However, veins and arteries were not distinguished by our methods of small vessel measurements. Nevertheless, in our population, pulmonary venous pressures (PCWP) at RHC were not different between groups, as well as the left heart functions at echocardiography. PH was always confirmed to be precapillary at RHC, and \%CSA measurements correlated with all values of pulmonary arterial pressures (systolic PAP, diastolic PAP, mean PAP), but not with pulmonary venous pressures (PCWP). Thus, we are reliably confident that postcapillary venous pressures cannot account for \%CSA variations. In addition, \%CSA measurements allowed a global quantification of vessel areas, irrespective of wall or lumen changes. We cannot speculate about the balance between vessel wall thickening and lumen narrowing in the pathophysiology of severe PH. Finally, patients with COPD without severe $\mathrm{PH}$ were a mix of patients with and without $\mathrm{PH}$, since the aim of the study was to discriminate severe $\mathrm{PH}$ among the whole population of COPD.

\section{CONCLUSION}

CT measurements of small vessels support a distinct vesselrelated phenotype in patients with COPD with severe $\mathrm{PH}$, and combined with WT and $\mathrm{PaO}_{2}$ parameters in the paw score, which may offer a non-invasive tool to select patients for RHC or for non-invasive follow-up in longitudinal study.

Contributors Conception and design: $\mathrm{FC}, \mathrm{GD}, \mathrm{PB}$ and $\mathrm{FL}$; analysis and interpretation: $F C, G D, P B$ and $F L$; drafting the manuscript for important intellectual content: $F C, G D, P B$ and $F L$; revising the manuscript for important intellectual content: $F C, G D, P B$ and $F L$; final approval of the manuscript: $F C, G D, C D, E B$, VF-M, P-OG, MM, FB, FP, RM, PB and FL.

Funding This study was achieved within the context of the Laboratory of Excellence TRAIL ANR-10-LABX-57.

Competing interests PB reports grants from Fondation du Souffle—Fonds de dotation Recherche en Santé Respiratoire, personal fees and non-financial support from Novartis, grants and personal fees from Pierre Fabre, personal fees and non-financial support from Chiesi, personal fees and non-financial support from Boehringer Ingelheim, personal fees and non-financial support from Takeda, personal fees and non-financial support from AstraZeneca, outside the submitted work. In addition, PB has a patent new compositions and methods of treating and/ or preventing COPD. Patent submitted 28 Jan 2015 (EP N¹5152886.6) pending. P-OG reports personal fees and non-financial support from Novartis, personal fees from Pierre Fabre, non-financial support from Chiesi, non-financial support from Takeda, personal fees and non-financial support from Boehringer Ingelheim, outside the submitted work.
Patient consent Obtained.

Ethics approval Our institutional review board and the local ethic committee.

Provenance and peer review Not commissioned; externally peer reviewed.

\section{REFERENCES}

1 Weitzenblum E, Hirth C, Ducolone A, et al. Prognostic value of pulmonary artery pressure in chronic obstructive pulmonary disease. Thorax1981;36:752-8.

2 Cooper R, Ghali J, Simmons BE, et al. Elevated pulmonary artery pressure. An independent predictor of mortality. Chest 1991;99:112-20.

3 Seeger W, Adir Y, Barberà JA, et al. Pulmonary hypertension in chronic lung diseases. J Am Coll Cardiol 2013;62(25Suppl):D109-16.

4 Thabut G, Dauriat G, Stern JB, et al. Pulmonary hemodynamics in advanced COPD candidates for lung volume reduction surgery or lung transplantation. Chest 2005;127:1531-6.

5 Chaouat A, Bugnet AS, Kadaoui N, et al. Severe pulmonary hypertension and chronic obstructive pulmonary disease. Am J Respir Crit Care Med 2005;172:189-94.

6 Chaouat A, Naeije R, Weitzenblum E. Pulmonary hypertension in COPD. Eur Respir J 2008;32:1371-85.

7 Scharf SM, Iqbal M, Keller C, et al. Hemodynamic characterization of patients with severe emphysema. Am J Respir Crit Care Med 2002;166:314-22.

8 Simonneau G, Gatzoulis MA, Adatia I, et al. Updated clinical classification of pulmonary hypertension. J Am Coll Cardiol 2013;62(25Suppl):D34-41.

9 Simonneau G, Robbins IM, Beghetti M, et al. Updated clinical classification of pulmonary hypertension. J Am Coll Cardiol 2009;54(1 Suppl):S43-54.

10 Weitzenblum E, Chaouat A. Severe pulmonary hypertension in COPD: is it a distinct disease? Chest 2005;127:1480-2.

11 Bankier AA, De Maertelaer V, Keyzer C, et al. Pulmonary emphysema: subjective visual grading versus objective quantification with macroscopic morphometry and thin-section CT densitometry. Radiology 1999;211:851-8.

12 Hackx M, Bankier AA, Gevenois PA. Chronic obstructive pulmonary disease: CT quantification of airways disease. Radiology 2012;265:34-48.

13 Dournes G, Laurent F, Coste F, et al. Computed tomographic measurement of airway remodeling and emphysema in advanced chronic obstructive pulmonary disease. Correlation with pulmonary hypertension. Am J Respir Crit Care Med 2015;191:63-70.

14 Matsuoka S, Washko GR, Dransfield MT, et al. Quantitative CT measurement of cross-sectional area of small pulmonary vessel in COPD: correlations with emphysema and airflow limitation. Acad Radiol 2010;17:93-9.

15 Uejima I, Matsuoka S, Yamashiro T, et al. Quantitative computed tomographic measurement of a cross-sectional area of a small pulmonary vessel in nonsmokers without airflow limitation. Jpn J Radiol 2011;29:251-5.

16 Matsuoka S, Washko GR, Yamashiro T, et al. Pulmonary hypertension and computed tomography measurement of small pulmonary vessels in severe emphysema. Am J Respir Crit Care Med 2010;181:218-25.

17 Estépar RS, Kinney GL, Black-Shinn JL, et al. Computed tomographic measures of pulmonary vascular morphology in smokers and their clinical implications. Am J Respir Crit Care Med 2013:188:231-9.

18 Dournes G, Coste F, Dromer C, et al. Evaluation des altérations bronchiques et vasculaires par TDM chez les patients BPCO compliqués d'hypertension Pulmonaire sévère. Journée Française de radiologie 2014;62:356.

19 Coste F, Dournes G, Dromer C, et al. Measurement of small pulmonary vessels by using computed tomography (CT) in COPD patients with severe pulmonary hypertension [abstract]. ERJ 2014;44 (supp 58);P2333.

20 Dournes G. CT measurement of small vessels as a tool to phenotype COPD subjects with severe pulmonary hypertension [abstract]. ESTI 2014;22:27

21 Wanger J, Clausen JL, Coates A, et al. Standardisation of the measurement of lung volumes. Eur Respir J 2005;26:511-22.

22 Miller MR, Hankinson J, Brusasco V, et al. Standardisation of spirometry. Eur Respir J 2005;26:319-38.

23 Montaudon M, Lederlin M, Reich S, et al. Bronchial measurements in patients with asthma: comparison of quantitative thin-section CT findings with those in healthy subjects and correlation with pathologic findings. Radiology 2009;253:844-53.

24 Berger $\mathrm{P}$, Perot $\mathrm{V}$, Desbarats $\mathrm{P}$, et al. Airway wall thickness in cigarette smokers: quantitative thin-section CT assessment. Radiology 2005;235:1055-64.

25 Montaudon M, Berger $\mathrm{P}$, de Dietrich $\mathrm{G}$, et al. Assessment of airways with three-dimensional quantitative thin-section $\mathrm{CT}$ : in vitro and in vivo validation. Radiology 2007;242:563-72.

26 Han MK, Agusti A, Calverley PM, et al. Chronic obstructive pulmonary disease phenotypes: the future of COPD. Am J Respir Crit Care Med 2010;182:598-604.

27 Dirksen A, MacNee W. The search for distinct and clinically useful phenotypes in chronic obstructive pulmonary disease. Am J Respir Crit Care Med 2013;188:1045-6.

28 Han MK, Kim MG, Mardon R, et al. Spirometry utilization for COPD: how do we measure up? Chest 2007;132:403-9. 
29 Han MK, Bartholmai B, Liu LX, et al. Clinical significance of radiologic characterizations in COPD. COPD 2009;6:459-67.

30 Galban CJ, Han MK, Boes JL, et al. Computed tomography-based biomarker provides unique signature for diagnosis of COPD phenotypes and disease progression. Nat Med 2012;18:1711-15.

31 Mohamed Hoesein FA, Schmidt M, Mets OM, et al. Discriminating dominant computed tomography phenotypes in smokers without or with mild COPD. Respir Med 2014;108:136-43.

32 Matsuura Y, Kawata N, Yanagawa N, et al. Quantitative assessment of cross-sectional area of small pulmonary vessels in patients with COPD using inspiratory and expiratory MDCT. Eur J Radiol 2013;82:1804-10.

33 Wright JL, Levy RD, Churg A. Pulmonary hypertension in chronic obstructive pulmonary disease: current theories of pathogenesis and their implications for treatment. Thorax 2005;60:605-9.

34 Wright IL, Petty T, Thurlbeck WM. Analysis of the structure of the muscular pulmonary arteries in patients with pulmonary hypertension and COPD: National Institutes of Health nocturnal oxygen therapy trial. Lung 1992;170:109-24.
35 Noureddine H, Gary-Bobo G, Alifano M, et al. Pulmonary artery smooth muscle cell senescence is a pathogenic mechanism for pulmonary hypertension in chronic lung disease. Circ Res 2011;109:543-53.

36 Barbera JA, Peinado VI, Santos S. Pulmonary hypertension in chronic obstructive pulmonary disease. Eur Respir J 2003;21:892-905.

37 Biernacki W, Gould GA, Whyte KF, et al. Pulmonary hemodynamics, gas exchange, and the severity of emphysema as assessed by quantitative CT scan in chronic bronchitis and emphysema. Am Rev Respir Dis 1989;139:1509-15.

38 Wells JM, lyer AS, Rahaghi FN, et al. Pulmonary artery enlargement is associated with right ventricular dysfunction and loss of blood volume in small pulmonary vessels in chronic obstructive pulmonary disease. Circ Cardiovasc Imaging 2015;8: pii: e002546.

39 Wells JM, Washko GR, Han MK, et al. Pulmonary arterial enlargement and acute exacerbations of COPD. N Engl J Med 2012;367:913-21.

40 Carlsen J, Hasseriis Andersen K, Boesgaard S, et al. Pulmonary arterial lesions in explanted lungs after transplantation correlate with severity of pulmonary hypertension in chronic obstructive pulmonary disease. J Heart Lung Transplant 2013;32:347-54. 